\title{
Anita Malfatti de Marta Rossetti Batista
}

Julio Roberto Katinsky ${ }^{1}$

BATISTA, Marta Rossetti. Anita Malfatti no tempo e no espaço. São Paulo: Editora 34, Edusp, 2006. 2 v.

0 livro de Marta Rossetti Batista intitulado Anita Malfatti no tempo e no espaço constitui-se de dois volumes: o primeiro trata da "Biografia e estudo da obra". O segundo é um "Catálogo da obra e documentação". Este último apresenta, além de uma introdução da autora e de uma bibliografia, o inventário de cerca de mil obras, mas, como adverte a pesquisadora, não pode ser considerado terminado, pois devem estar ainda esquecidas em alguma gaveta ou fundo de armário obras que a artista - ou mesmo seus familiares - subestimou. As obras recolhidas são acompanhadas de catalogação de acordo com as normas estabelecidas, sua localização quando foram expostas e, às vezes, de alguns comentários. Raríssimos artistas brasileiros podem contar com um trabalho tão minucioso e conduzido com tanto zelo. Acresce que, iniciado em 1964, com uma bolsa de iniciação científica da Fapesp, sob a orientação e responsabilidade do professor Flávio Motta, prosseguiu por iniciativa da pesquisadora, sendo publicado em dezembro de 2006.

Entretanto, eu acrescentaria um ano a esse período. $\mathrm{Na}$ realidade, a pesquisa começou em 1963 com um planejamento do estudo da obra de Anita, Tarsila do Amaral e Flávio de Carvalho, tendo Flávio Motta se encarregado das primeiras propostas de catalogação da obra de Cândido Portinari, desaparecido no ano anterior. Pouco tempo depois, seu filho Antônio Cândido iniciou o inventário do grande pintor brasileiro.

No caso de Anita Malfatti são quarenta e três anos de pesquisa, quase tanto tempo quanto o de vida artística da pintora brasileira, se arbitrariamente estabelecemos o período de 1914 (quando voltou da Alemanha) até 1964, quando morreu, ou

1 Professor Titular da Faculdade de Arquitetura e Urbanismo da Universidade de São Paulo. 
seja, cinqüenta anos; graças a esse trabalho, podemos usufruir de uma visão bem mais precisa da contribuição da artista paulista para a cultura brasileira do século XX do que a da maior parte de seus contemporâneos. Entretanto, esse trabalho conduzido sem auxílios, ou incentivos financeiros, não pode ser explicado profissionalmente: é, antes de tudo, um milagre afetivo.

0 primeiro livro, a biografia da artista, apresenta a mesma minuciosa busca de comprovações documentais, mas agora, temos um vasto painel no qual se articulam a vida de uma paulistana nascida nos finais do século XIX, dentro de uma família de classe média alta, com parentes excepcionalmente escolarizados para o tempo e lugar - uma cidade provinciana e consciente de seu provincianismo e, portanto, sedenta de transformações que a colocassem ao mesmo nível pelo menos da capital da República, e mais, quem sabe, das grandes cidades de nossa "civilização" ocidental, científica e tecnologicamente com uma indústria que estava em vias de suplantar a da maior cidade industrial brasileira, o Rio de Janeiro.

E finalmente, mas não menos importante, com novas preocupações com as artes, bem atestadas pelo lançamento de um teatro oficial (municipal!) em 1908 antes mesmo que a própria capital da República cogitasse, com recursos federais, de construir o seu.

Marta, discretamente, poucas referências faz aos acontecimentos sociais que abalaram o mundo e o país, bem como trata com isenção as perturbações desse século tão revolucionado e que se prolonga pelo início deste século que estamos vivendo.

Todos os autores que trataram de Anita Malfatti, de maneira mais suave ou mais áspera, colocam-na como figura central de uma espécie de terremoto cultural, com sua exposição de 1917, na qual ela exibiu pinturas feitas na Alemanha e nos Estados Unidos até 1916.

Parece que havia um consenso entre amigos e inimigos de que o choque provocado por essas pinturas não só abalou o "bem comportado" ambiente cultural paulistano, como também a reação dos elementos mais conservadores prejudicou definitivamente o desenvolvimento posterior da pintora.

Um dos méritos e não pequeno do livro de Marta é que registra inequivocamente um aspecto dessa artista, ou seja, uma grande homogeneidade em sua longa carreira artística: pode-se acompanhar ao longo de todos os anos o desenvolvimento do seu desenho, como atividade artística autônoma, mesmo que ela não desse muita atenção a ele.

0 século $X X$, parece, foi o século da arquitetura e do desenho no Brasil, mais do que da pintura e da escultura. 
Desenho, entendida também a gravura. Ainda que apoiado em experiências européias e norte-americanas, o desenho brasileiro, principalmente a partir da caricatura, cedo se torna autônomo como meio expressivo e, no ato, firma-se como atividade artística também autônoma, independente da sua condição de suporte de outras atividades artísticas, a pintura por exemplo, que na Itália é colecionada como "sinopia”.

Como é sabido, o desenho lentamente adquiriu, junto com a caricatura, a condição de "arte maior" na Europa. E no Brasil, no século XX. Pois examinando os documentos recolhidos por Marta Rossetti Batista, nós verificamos que as apreciações críticas sobre a pintura de Anita não valem para seu desenho. Como aliás, para sua companheira de jornada mais próxima, Tarsila do Amaral. Um dos grandes méritos da exposição de 1969, no MAM do Rio de Janeiro com curadoria da senhora Aracy Amaral, foi justamente tornar pública uma enorme coleção de desenhos da artista, até então praticamente desconhecidos. Também nesse caso revelou-se um acervo homogêneo de obras, sem hesitações, sem saltos, e de uma qualidade que assegura a ambas, Anita e Tarsila, uma posição de destaque entre os artistas brasileiros do século XX. Os jornais de São Paulo noticiaram o grande empenho em realizar o primeiro inventário com adequados recursos da obra de Tarsila do Amaral, provavelmente nos mesmos moldes deste de Anita. Se esse fato ocorrer, nós podemos saudá-lo como uma nova etapa na consolidação da arte no Brasil.

Convém não esquecer, ainda que seja até certo ponto secundário, mas o único prêmio de artista plástico brasileiro com grande repercussão mundial na Bienal de Veneza foi aquele outorgado ao desenho de Aldemir Martins, na década de 1960 do século passado.

Em relação à pintura de Anita Malfatti, também vamos encontrar não só uma apreciação estrita pela valorização do período "expressionista" da artista, mas mesmo uma depreciação franca de seus ensaios posteriores, principalmente pelos seus companheiros modernistas da Semana de Arte Moderna. Lembro-me quando Rubem Borba de Moraes, em 1964-1965, ao nos dar algumas aulas sobre biblioteconomia, no curso de pós-graduação organizado por Flávio Motta na FAU, em seu apartamento próximo, nos convidou para ver sua biblioteca, e reiterou em uma conversa extremamente rica que Anita Malfatti tinha sido importante com suas pinturas alemãs e norte-americanas até 1924, mas que com a ida à Europa, como pensionista do Estado, sua pintura perdera completamente o interesse, como contribuição cultural. Mas não é a mesma atitude, um pouco menos agressiva, é verdade, em relação a 
Tarsila? Depois de Abaporu em 1928, tudo que Tarsila fez não foi descaminho? E isso não foi sacramentado pelos inimigos declarados do "modernismo", mas pelos seus mais legítimos representantes.

Ora, essa atitude também é uma constante durante todo o século. Pois Belmiro de Almeida não é quase só conhecido pelo seu brejeiro e frívolo painel Arrufos, adquirido antes da tinta ter secado completamente, pelo próprio Governo Federal, ainda no século XIX, enquanto sua pintura densa do período pontilhista só mereceu um breve comentário do também excelente pintor José Maria dos Reis, em precioso livro sobre o artista. 0 exame, mesmo superficial, da obra de Belmiro de Almeida nos ensina que seu apuro no corte geométrico dos planos articulados de suas vistas urbanas, hauridos do mestre George Seurat, foi um poderoso incentivo para uma nova reflexão (na época) sobre a decomposição cezanniana que resultou no cubismo. Entretanto a crítica brasileira da época junto com Arrufos valorizava o quadro 0 importuno de seu amigo Almeida Júnior, outro monumento da frivolidade de uma classe contente consigo mesma.

A pergunta que cabe, e que deverá ser respondida por gente mais bem equipada, é sobre o que perseguia a crítica brasileira de artes plásticas durante o século XX. Nada mais ilustrativo dessa postura do que a polêmica surgida em 1944, após a exposição de Lasar Segall de 1943 promovida pelo Ministério de Educação e Saúde na capital da República, e minuciosamente documentada no capítulo "Fazer História” (p. 433 e ss.) do livro de Marta.

Em relação à reivindicação de pioneirismo na implantação da arte moderna no Brasil defendida para Lasar Segall por Rubem Navarra, Mário de Andrade protestou publicamente contra essa atribuição insistindo sobre a prioridade da exposição de Anita em 1917 (em detrimento da exposição de Segall em 1913), devido à nenhuma repercussão da segunda, enquanto a exposição de 1917 tivera a mais violenta manifestação de vontades desencontradas.

Ora, poder-se-ia argumentar com Rubem Navarra que a ausência de repercussão também é uma manifestação. Principalmente se nos lembrarmos, não só de Belmiro, mas também de Seelinger, Eliseu Visconti, todos anunciadores (hoje sabemos) da repercussão no Brasil das novas correntes da arte contemporânea e que não encontraram uma acolhida adequada no interior dos grupos de intelectuais atuantes na época. Ou do príncipe Zamoyski, que passou trinta anos no Brasil. 0 príncipe só voltou à Polônia (comunista) quando sentiu seu fim próximo 
e, como bom aristocrata, decidiu enterrar-se em seu solo católico e ancestral.

Boa parte da crítica que se praticava então pode ser resumida na afirmação de que sua função seria, no caso dos críticos consagrados, explicitar o que os artistas deveriam querer. E os novos críticos queriam que os artistas quisessem aquilo que eles (críticos) queriam que eles, artistas, quisessem.

Sobre quem era pioneiro ou não, a propósito da reivindicação de pioneirismo em arquitetura, Lúcio Costa nos meados da década de 1950 respondeu sarcasticamente que "arquitetura não é far-west”. Aliás, arte também não é far-west. E também não é corrida de obstáculo.

Há entretanto no livro de Marta uma afirmação à p. 375 que me parece exagero e também que pode levar à confusão:

Logo, o foco das principais manifestações da vanguarda artística brasileira se deslocaria para o Rio de Janeiro, com Portinari, 'pintor oficial' e com a nascente arquitetura moderna.

Exagero porque, como vimos nos parágrafos anteriores, já desde o início do século havia sinais de um pensamento novo agitando os artistas plásticos da Capital Federal. E, na década de 1920, tanto Cícero Dias como Ismael Nery não dependeram diretamente da escandalosa Semana Paulista.

Também a expressão "pintor oficial" pode induzir a erro. Se na década de 1940 Portinari teve encomendas "oficiais" como os painéis do Ministério da Educação e Saúde e da Pampulha, nós não podemos deixar de reconhecer que as encomendas oficiais nessas décadas foram, digamos assim, mais democraticamente distribuídas: Tarsila trabalhou para o Estado (por intermediação inclusive de Taunay), bem como Helios Seelinger (Horto Florestal), Arquimedes Memória (Ministério da Fazenda) ou Cristiano S. das Neves (Ministério da Guerra), com obras muito mais custosas que as chamadas "oficiais" dos arquitetos modernos. Mais importante, ainda que de forma miseravelmente incipiente, alguns artistas, mesmo violentamente discriminados, puderam realizar um trabalho nada desprezível, embora não clamoroso. Não fosse o apoio decidido de uma parte da intelectualidade, Paulo Rossi Osir não poderia manter seu atelier de azulejos "Osirarte" e os magníficos azulejos de Portinari para o Ministério não existiriam. Nem o painel extraordinário de fecho da parede de fundo da capela de São Francisco da Pampulha, com a "nacionalização" do Picasso de Guernica, que é um dos pontos altos da arte brasileira do período. Aliás, esta capela, 
com sua iluminação zenital dirigida para o painel de fundo do altar (abside?), parece ter sido concebida para destacar o afresco também de Portinari. Essas pinturas, essas edificações modernas não expressam o populismo do Estado Novo. Antes foram impostas ao poder central nessas décadas (1940 e 1950) num período de grande confusão política aqui e no mundo.

Já vem o peso do mundo com suas fortes sentenças Sobre a mentira e a verdade desabam as mesmas penas Apodrecem nas masmorras Juntas, a culpa e a inocência. (Cecília Meireles)

A exposição de 1917 e a Semana de Arte Moderna ocupam pouco mais de cem páginas no livro de Marta, sendo um dos pontos culminantes a crítica de Monteiro Lobato, posteriormente (1919) publicada no livro Idéias de Jeca Tatu com o título "Paranóia ou Mistificação - a propósito da Exposição Malfatti".

0 curioso dessa estranha polêmica é que o autor concede altas qualidades à artista, como Marta transcreve e que, como exemplo, reproduzo:

É um dever dizê-lo, porque poucos artistas se apresentaram com tantos elementos de triunfo como a senhorita Malfatti: seria profundamente lamentável ver perder-se num desvio de orientação estética uma organização artística como a dessa jovem pintora. (p. 230).

Parece que as interpretações divergem ligeiramente, segundo Marta, mas também parece claro que o ataque não se dirigiu à artista, mas à "orientação estética" de alguns jovens artistas. Pois é a Oswald de Andrade que se dirige este parágrafo:

Arte moderna, eis o escudo, a suprema justificação. Na poesia também surgem, às vezes, furúnculos desta ordem, provenientes da cegueira nata de certos poetas elegantes, apesar de gordos e a justificativa é sempre a mesma: arte moderna. Como se não fossem moderníssimos esse Rodin que acaba de falecer deixando após si uma esteira luminosa de mármores divinos;... (p. 208)

Como bem acentua Marta.

Mas às interpretações já firmadas apresento uma outra apoiada em primeiro lugar em uma série de artigos de Sérgio Milliet na revista Anhembi de Paulo Duarte, nos quais estuda 
a poesia moderna paulista, especialmente dos poetas modernistas da Semana. Nesses artigos Milliet chama a atenção para a rejeição de uma visão de um Brasil como prolongamento da tradição lusitana, e para a acentuação da contribuição dos novos estrangeiros chegados há pouco, como os italianos (imigrantes). Essa colocação de Milliet se vê refletida nos contos de Alcântara Machado (Brás, Bexiga e Barra Funda) e nos primeiros contos da década de 1920 de Mário de Andrade.

Em segundo lugar, em uma denúncia publicada na Folha de S. Paulo por Cláudio Abramo (pouco antes de morrer) na qual o respeitado jornalista afirmou, baseado em sua experiência pessoal, o desprezo de Monteiro Lobato por mais um italianinho a lhe solicitar apoio, acusando-o de chauvinista e xenófobo. Talvez Abramo tivesse chegado em má hora, em momento difícil para Lobato, que também era um não muito feliz empresário. Mas após esse alerta, podemos constatar na obra do escritor traços de desconfiança em relação aos imigrantes. No que frações de sua classe eram pródigas (Ver Contos de Belazarte de Mário de Andrade).

0 senhor Francisco de Assis Barbosa em ensaio acrescentado à edição facsimilar, patrocinada pelo senhor José Mindlin, do primeiro livro infantil de Monteiro Lobato reproduz parte do editorial do senhor Júlio Mesquita, de 1916, no jornal O Estado de S. Paulo, a propósito da Revista do Brasil:

0 que há por detrás do título desta Revista e dos nomes que a patrocinam é uma coisa simples e imensa: o desejo, a deliberação, a vontade firme de constituir um núcleo de propaganda nacionalista.

...

Vivemos desde que existimos como nação, quer no Império quer na República, sob a tutela direta ou indireta, se não política ao menos moral do estrangeiro.

Mas essa constatação não pretende insinuar que a "oligarquia cafeeira" inteiriça seria chauvinista ou xenófoba. Mesmo porque as poupanças do café em grande parte eram absorvidas desde 1860 pela grande indústria têxtil que se instalava e pelas ferrovias. Estas exigiram a criação da Escola Politécnica e do ensino técnico, elementos necessários para o desenvolvimento industrial paulista. Também não encontrou guarida em toda a "oligarquia cafeeira" a caricatura predominantemente paulista do fascismo italiano no Brasil. Ao contrário, Monteiro Lobato, até onde se sabe, manteve distância do integralismo, seu sigma e anauê. Quanto a sua visão de artes plásticas, à distância de oito décadas e com os documentos dis- 
poníveis, só se pode conjecturar que o escritor, como a imensa maioria dos brasileiros, inclusive os intelectuais, alienados do pensamento moderno em sua interpretação da realidade, só podia se apoiar na ideologia dominante no país, escombro da visão jesuítica de mundo, levemente trabalhada pelo positivismo de Augusto Comte.

Apesar dos textos expostos com grande firmeza, o nosso escritor era tão inseguro e despreparado quanto seus opositores mais jovens. Perceberia ele que os desenhos de Voltolino, seu ilustrador de eleição para seus primeiros livros infantis, estavam mais próximos de Anita do que os dos ilustradores futuros?

Essa situação contraditória se positiva ainda mais quando se verifica que o seu sócio desde 1917 na Revista do Brasil, Paulo Prado, é o mesmo "barão do café" que iria patrocinar a "Semana de Arte Moderna" no Municipal em 1922. Mesmo assim, podemos dizer que a polêmica, tendo como pretexto a jovem artista paulistana, serviu para distanciar dois grupos de nacionalistas: o primeiro caracterizado por um nacionalismo cujo chauvinismo e xenofobia iriam cada vez mais predominar, culminando na ideologia separatista de 1932 e na ideologia integralista de 1935 e 1937. 0 outro grupo nacionalista, sob certos aspectos ainda vigente, ecumênico em relação aos "novos brasileiros", cada vez mais libertário, inclusive absorvendo, através das correntes socialistas dos vários matizes, a incorporação do moderno pensamento crítico - Sérgio Buarque de Holanda (Max Weber), Caio Prado Júnior (Marx e Engels), Gilberto Freyre (a moderna antropologia norte-americana), Afonso Arinos (Conde Sforza, Benedetto Croce), José Honório Rodrigues (Benedetto Croce).

Em relação a Anita, teria o grande escritor se arrependido de seu importuno e impertinente ataque? Difícil é saber sem documentos ou testemunhos do tempo, principalmente hoje, quando a maior parte de seus contemporâneos já desapareceu. Principalmente porque a distância estética entre Lobato e seus modernistas opositores não era tão grande assim. Se Oswald de Andrade reconheceu, generosamente, que Urupês está na base, na origem da atitude crítica de alguns modernistas, por outro lado, as irreverências modernistas não terão contaminado Lobato principalmente na boneca Emília de sua literatura infantil, que de mamulengo (boneco mudo e desengonçado) da primeira história, evolui para a irreverente e imaginosa personagem central das últimas?

Difícil saber, mas as pessoas que podiam influir na decisão de outorgar em 1924 o "pensionato artístico" do Estado a Anita Malfatti, mais do que pertencentes à mesma "oligarquia", 
pertenciam como Dona Olívia G. Penteado à mesma família do sócio de Monteiro Lobato (Paulo Prado) e, provavelmente, eram seus amigos e admiradores. Ele não saberia nada dessas cogitações prévias? $\mathrm{Ou}$, quem sabe, não teria dado seu assentimento? 0 prêmio de Pensionato Artístico em Paris para Anita Malfatti parece mais um desagravo, dada sua idade, do que esperança em jovem talentosa e promissora. 0 pensionato artístico seria, genericamente, alvo de pilhérias em 1928 na obra Macunaima de Mário de Andrade. Por outro lado, tudo isso tem pouca importância: a cada pessoa sua sentença, e à humanidade, seu destino.

Não podemos deixar de assinalar o surgimento de artistas oriundos das classes próximas ao proletariado principalmente a partir dos anos 1930, e junto com eles, de "críticos de classe", que a partir dos anos trinta procuraram estigmatizar o modernismo como um entretenimento da alta burguesia paulista opressora e prepotente. Sem dúvida os modernistas mais em evidência eram bem abonados como Oswald de Andrade e Tarsila, e a Semana foi patrocinada por Paulo Prado e Olívia G. Penteado, mas a obra posterior da maior parte deles não confirma essa postura hedonista que se lhes queria impingir. Muito ao contrário, foram esses mesmos representantes da elite brasileira que acolheram esses artistas e mesmo suas reivindicações (legítimas) de ascensão social: Carlos Prado, Mário Pedrosa, Caio Prado, Oswald de Andrade, Tarsila, Mário de Andrade e Anita.

0 livro de Marta nos mostra, com sua rica documentação, que ela se desvencilhou com isenção dos prejulgamentos tanto dos detratores do "modernismo", como de seus cultores:

Mas entre sua produção variada como técnica e temática, havia linhas contínuas: as tabuinha, as naturezas mortas e os retratos. A pintora executou muitos retratos, fossem de familiares, alunos e amigos, ou 'de encomenda'. Foi no retrato que Anita Malfatti conciliou melhor subsistência e arte, nos anos 30. Se não eram mais obras de vanguarda - no sentido que o foram $O$ homem amarelo e $A$ mulher de cabelos verdes - são obras bem realizadas e merecem ser estudadas". (p. 418)

Não só essa afirmação nos parece básica para qualquer apreciação futura, como, tudo indica, para uma apreciação mais isenta de toda a obra da artista: na exposição de 1917, ao lado do excelente retrato do pintor Baylinson (Retrato de Bajley), outros desenhos e caricaturas parecem ser meros exercícios escolares. 
Aliás, toda obra de Anita merece uma avaliação que poderá ser feita se for organizada uma grande retrospectiva da pintora e que será também uma homenagem a sua mais afetuosa biógrafa. Marta já não está entre nós, e só me cabe neste momento oferecer sua vida para os jovens como espelho e iluminação fazendo como o que ela fez e que nos serve de modelo: trabalhou cotidianamente, e com todo seu afeto discreto, para o melhoramento político-social do homem. 